\title{
Chronic bronchitis, work related respiratory symptoms, and pulmonary function in welders in New Zealand
}

\author{
Lisa M Bradshaw, David Fishwick, Tania Slater, Neil Pearce
}

\begin{abstract}
Objectives-A cross sectional study of respiratory symptoms and lung function in welders was performed at eight New Zealand welding sites: 62 current welders and 75 non-welders participated.

Methods-A questionnaire was administered to record demographic data, smoking habit, and current respiratory symptoms. Current and previous welding exposures were recorded to calculate a total lifetime welding fume exposure index. Forced expiratory volume in one second $\left(F_{E V}\right)$, forced vital capacity (FVC), and peak expiratory flow (PEF) were measured before the start of the shift.
\end{abstract}

Results-There were no significant differences in ethnicity, smoking habits, or years of work experience between welders and non-welders. Symptoms of chronic bronchitis were more common in current welders $(11.3 \%)$ than in non-welders $(5.0 \%)$. Of those workers with a cumulative exposure index to welding fume $\geqslant 10$ years, $16.7 \%$ reported symptoms of chronic bronchitis compared with $4.7 \%$ of those with a cumulative exposure index $<4$ years (odds ratio (OR) 4.1, 95\% confidence interval $(95 \% \mathrm{CI}) 0.90$ to 17.6$)$. Workers with chronic bronchitis had significantly lower measures of baseline PEF ( $p=0.008$ ) and $F E V_{1} / F V C$ ratio $(p=0.001)$ than workers without chronic bronchitis. Multivariate analysis showed that current smoking (OR 9.3, 1.0 to 86.9) and total exposure index to welding fumes $>10$ years (OR 9.5, 1.3 to 71.9$)$ were independent risk factors for chronic bronchitis. The report of any work related respiratory symptom was more prevalent in welders $(30.7 \%)$ than non-welders $(15.0 \%)$ and workers with these symptoms had significantly lower FEV $_{1}(p=0.004)$ and FVC $(p=0.04)$ values. Multivariate analysis identified a high proportion of time spent welding in confined spaces as the main risk factor for reporting these symptoms (OR $2.8,1.0$ to 8.3).

Conclusion-This study has documented a high prevalence of symptoms of chronic bronchitis and other work related respiratory symptoms in current welders. Also, workers with chronic bronchitis had reduced PEF and FEV ${ }_{1} / F V C$ compared with those without chronic bronchitis. These symptoms related both to cigarette smok- ing and a measure of lifetime exposure to welding fume.

(Occup Environ Med 1998;55:150-154)

Keywords: welding fume; lung function

Industrial welding has historically been associated with lung disease and current welding techniques continue to produce many potential exposures to particulates and gases. ${ }^{1}$ Many components of welding can potentially affect the lung although individual workers may well respond differently when exposed to welding fumes and gases. ${ }^{12}$ Therefore, there are many respiratory problems that may be associated with welding; these vary from acute responses - such as that seen in metal fume fever $^{3}$ usually associated with zinc oxide inhalation - to less common cases of hypersensitivity pneumonitis and chronic sequelaesuch as welding related pneumoconioses. ${ }^{4}$

Several previous studies have noted chronic bronchitis to be more prevalent in welders, ${ }^{5-7}$ however, this association has not been found in all studies, ${ }^{8}$ and there is potential for confounding from other relevant exposures, such as cigarette smoking and previous occupational exposures. In 1991 a small New Zealand study ${ }^{9}$ noted a particularly high level of respiratory symptoms in a group of welders, and that $38 \%$ of current welders complained of symptoms of chronic bronchitis. Although there was no comparison group, this prevalence was considered to be higher than expected.

We have accordingly carried out a cross sectional study of welders in New Zealand. The findings for changes in lung function across a shift in current welders (compared with current non-welders) have been reported elsewhere. ${ }^{10}$

We report here the findings for chronic bronchitis and work related respiratory symptoms and their relations to lifetime exposure to welding products, work practices, and cigarette smoking.

\section{Methods}

The basic methodology of the survey has been reported previously. ${ }^{10}$ Briefly, eight New Zealand engineering sites known to regularly involve welding as part of their industrial process were approached after liaison with the Engineers Union of New Zealand. All current welders at each site and either all non-welders or a random subsample (at larger sites) of nonwelders were asked to participate. Most of the 
Table 1 Characteristics of study participants by factory site

\begin{tabular}{|c|c|c|c|c|c|c|c|c|}
\hline \multirow[b]{2}{*}{ Factory } & \multirow[b]{2}{*}{ Workers (n) } & \multirow[b]{2}{*}{$\begin{array}{l}\% \text { Male } \\
(n(\%))\end{array}$} & \multirow[b]{2}{*}{$\begin{array}{l}\text { Mean age } \\
(y)\end{array}$} & \multicolumn{3}{|l|}{ Smoking } & \multicolumn{2}{|l|}{ Ethnicity } \\
\hline & & & & $\begin{array}{l}\text { Current } \\
(n(\%))\end{array}$ & $E x(n(\%))$ & $\begin{array}{l}\text { Never } \\
(n(\%))\end{array}$ & $\begin{array}{l}\text { Polynesian } \\
(n(\%))\end{array}$ & Other $(n(\%))$ \\
\hline 1 & 27 & $27(100)$ & 40.9 & $9(33.3)$ & $8(29.6)$ & $10(37.0)$ & $2(7.4)$ & $25(92.6)$ \\
\hline 2 & 13 & $13(100)$ & 38.5 & $1(7.7)$ & $4(30.8)$ & $8(61.5)$ & $0(0.0)$ & $13(100.0)$ \\
\hline 3 & 8 & $8(100)$ & 35.0 & $3(37.5)$ & $2(25.0)$ & $3(37.5)$ & $5(62.5)$ & $3(37.5)$ \\
\hline 4 & 17 & $17(100)$ & 42.2 & 9 (52.9) & $0(0.0)$ & $8(47.1)$ & $12(70.6)$ & $5(29.4)$ \\
\hline 5 & 10 & $10(100)$ & 34.8 & $4(40.0)$ & $3(30.0)$ & $3(30.0)$ & $1(10.0)$ & $9(90.0)$ \\
\hline 6 & 29 & $29(100)$ & 38.4 & $19(65.5)$ & $5(17.2)$ & $5(17.2)$ & $2(6.9)$ & $27(93.1)$ \\
\hline 7 & 15 & $10(66.7)$ & 32.1 & $8(53.3)$ & $1(6.7)$ & $6(40.0)$ & $10(66.7)$ & $5(33.3)$ \\
\hline 8 & 18 & $17(94.4)$ & 42.7 & $5(27.8)$ & $6(33.3)$ & 7 (38.9) & $3(16.7)$ & $15(83.3)$ \\
\hline Totals & 137 & $131(95.6)$ & 38.8 & $58(42.3)$ & $29(21.2)$ & $50(36.5)$ & $35(25.5)$ & $102(74.5)$ \\
\hline
\end{tabular}

welders studied worked with mild steel or mild steel and stainless steel as a base metal, with either gas tungsten arc welding (TIG) or gas metal arc welding (particularly MIG) techniques. All welders in this study were working indoors, and none of the sites was a shipyard, although site one was a marine engineering firm. The non-welders generally worked as fitters or turners or in a similar occupation in the same environment.

QUESTIONNAIRE

The study questionnaire included demographic data, smoking, questions about work related respiratory symptoms (in particular current phlegm, wheeze, or recent cough, chest tightness, and shortness of breath) and also selected questions from the European Community respiratory health survey. ${ }^{11}$ Smoking categories were defined as current smoker, ex-smoker (ever having smoked at least one cigarette a day for a year) but not currently smoking, or never a smoker of tobacco.

Polynesian ethnicity was defined as any person of Maori or Pacific Island descent.

Chronic bronchitis was defined as regular phlegm production at any time during the day or night for at least three months of the year and for at least two years. Work related respiratory symptoms were defined as either cough, wheeze, chest tightness, or shortness of breath reported to be worse at work or improving on rest days. For the purposes of subsequent analyses, all workers with at least one of these work related respiratory symptoms were grouped together.

SITES

All people studied worked a day shift at one of the eight study sites. Welding practice varied from marine heavy engineering to one site involved with light engineering.

Table 2 Demographic data (n (\%)), smoking habit, and prevalence of chronic bronchitis in current welders, ex-welders, and non-welders

\begin{tabular}{lccc}
\hline & $\begin{array}{l}\text { Current welders } \\
(n=62)\end{array}$ & Ex-welders $(n=35)$ & Non-welders $(n=40)$ \\
\hline Men & $61(98.4)$ & $35(100)$ & $35(87.5)$ \\
Polynesian & $16(25.8)$ & $8(22.9)$ & $11(27.5)$ \\
Current smoker & $29(46.8)$ & $12(34.3)$ & $17(42.5)$ \\
Ex-smoker & $10(16.1)$ & $9(25.7)$ & $10(25.0)$ \\
Non-smoker & $23(37.1)$ & $14(40.0)$ & $13(32.5)$ \\
Chronic bronchitis & $7(11.3)$ & $1(2.9)$ & $2(5.0)$ \\
Work related respiratory & $19(30.7)$ & $6(17.1)$ & $6(15.0)$ \\
$\quad$ & & & \\
\hline
\end{tabular}

CURRENT WELDING EXPOSURE

The current occupation and the duration of employment were recorded. To group by job on the study day, if the worker carried out a weld on the study day then that person was classed as a current welder. Ex-welders were defined as workers who had reported ever being a welder during their working life, but not currently working as a welder. Current welders were likely to be exposed to mixes of metals (particularly iron, and chromium) and gases (NO, $\mathrm{NO}_{2}$, ozone) as well as other particulates.

PREVIOUS WELDING EXPOSURE

All workers were asked to describe their previous lifetime exposure in terms of sequential periods spent in differing jobs, and the associated proportion of the day spent welding (if appropriate) in each of these posts. The effective exposure in years (per job) was calculated as the product of these two variables, and the cumulative measure (in years) was calculated by summing all the individual exposures for each job. This estimate is subsequently referred to as the total exposure index.

\section{EXPOSURE VARIABLES USED FOR ANALYSIS}

The total exposure index was ranked into three categories for multivariate analysis, and the proportion of time currently spent welding in a confined space was also divided into three categories.

\section{PULMONARY FUNCTION}

All workers in the study were asked to perform pulmonary function tests with a calibrated portable spirometer (Alpha Spirometer, Vitalograph). Lung function measurements were taken before the shift started, before any exposure to welding fume on the study day and were carried out according to the guidelines set by Quanjier et al. ${ }^{12}$ The best of three forced expiratory manoeuvres within $5 \%$ was used to record all measured values. Forced expiratory volume in one second $\left(\mathrm{FEV}_{1}\right.$ in litres), forced vital capacity (FVC in litres), peak expiratory flow (PEF in $1 / \mathrm{min}$ ) and $25 \%-75 \%$ forced expiratory flow $\left(\mathrm{FEF}_{25-75}\right.$ in $\left.1 / \mathrm{min}\right)$ were measured with the best value of three forced expiratory manoeuvres in the standing position. The ratio of $\mathrm{FEV}_{1} / \mathrm{FVC}$ was then calculated and subsequently referred to as $\mathrm{FEV} \%$. All variables were then converted into the percentage predicted $^{12}$ value for each person with the 
Table 3 Factors associated with having chronic bronchitis (odds ratios shown both unadjusted and adjusted)

\begin{tabular}{|c|c|c|c|c|}
\hline & $\begin{array}{l}\text { Chronic bronchitis } \\
(n=10)\end{array}$ & $\begin{array}{l}\text { No chronic } \\
\text { bronchitis }(n=127)\end{array}$ & $\begin{array}{l}\text { Odds ratio }(95 \% \\
\text { CI) }\end{array}$ & $\begin{array}{l}\text { Adjusted odds } \\
\text { ratio }(95 \% \text { CI) } \dagger\end{array}$ \\
\hline \multicolumn{5}{|l|}{ Smoking: } \\
\hline Never & 1 & 49 & $1.0^{\star}$ & $1.0^{\star}$ \\
\hline Ex-smoker & 2 & 27 & $3.6(0.3$ to 42.0$)$ & $5.6(0.4$ to 4.6$)$ \\
\hline Current & 7 & 51 & $6.7(0.8$ to 56.8$)$ & $9.3(1.0$ to 86.9$)$ \\
\hline \multicolumn{5}{|l|}{ Ethnicity: } \\
\hline Other & 7 & 95 & $1.0^{\star}$ & $1.0^{\star}$ \\
\hline Polynesian & 3 & 32 & $1.3(0.3$ to 5.2$)$ & $1.2(0.2$ to 6.2$)$ \\
\hline \multicolumn{5}{|l|}{ Age: } \\
\hline $17-24$ & 1 & 17 & $1.0^{\star}$ & $1.0^{\star}$ \\
\hline $25-40$ & 6 & 55 & $1.9(0.2$ to 16.5$)$ & $1.3(0.1$ to 13.2$)$ \\
\hline$>40$ & 3 & 55 & $0.9(0.1$ to 9.5$)$ & $0.2(0.0$ to 3.6$)$ \\
\hline \multicolumn{5}{|c|}{$\begin{array}{l}\text { Time spent currently welding in confined spaces } \\
(\%) \text { : }\end{array}$} \\
\hline $0-2$ & 5 & 90 & $1.0^{\star}$ & $1.0^{\star}$ \\
\hline $2-10$ & 2 & 14 & $2.6(0.5$ to 14.6$)$ & $1.5(0.2$ to 13.1$)$ \\
\hline$>10$ & 3 & 23 & $2.4(0.5$ to 10.6$)$ & $1.8(0.3$ to 10.2$)$ \\
\hline \multicolumn{5}{|c|}{ Total exposure index (y): } \\
\hline $0-4$ & 4 & 81 & $1.0^{\star}$ & $1.0^{\star}$ \\
\hline $4-10$ & 2 & 26 & $1.6(0.3$ to 9.0$)$ & $2.1(0.3$ to 15.5$)$ \\
\hline$>10$ & 4 & 20 & $4.1(0.9$ to 17.6$)$ & 9.5 (1.3 to 1.9$)$ \\
\hline
\end{tabular}

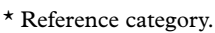

† Adjusted for all other factors in table.

equations integral in the spirometer. Appropriate reduction $(15 \%)$ was made to the predicted value for those workers of Polynesian origin as suggested by a widely accepted standard. ${ }^{12}$

DATA ANALYSIS

All analyses were by PC SAS ${ }^{13}$. Continuous variables were compared between groups by estimating the mean (SD) and the associated unpaired $t$ test. Prevalence odds ratios (ORs) (and their 95\% confidence intervals (95\% CIs)) were calculated with the MantelHaenszel method. ${ }^{14}$ Logistic regression ${ }^{15}$ was used to calculate ORs (adjusted for age, sex, cigarette smoking, and other variables in the model) for each risk factor. Significance was taken at the $5 \%$ level throughout $(\mathrm{p}<0.05)$.

All workers in this study gave written informed consent to take part, and the study was approved by the Wellington ethics committee.

\section{Results}

Table 1 shows demographic details and smoking habits of the 137 workers who took part in the study; seven workers (four welders, three non-welders) declined to participate in the study, resulting in an overall response rate of $95.1 \%$. The mean age and smoking habits of the workers differed slightly at each workplace and there was also a large difference in ethnicity, which related primarily to the different geographical areas in which the engineering firms were situated. Two sites currently provided local extraction ventilation adjacent to the weld and only one welder (plasma technique) used a respirator.

There were no significant differences in the results between MIG and non-MIG welders, and therefore the results for all welders have been combined for further analysis.

Sixty two workers $(45.3 \%$ of the study population) performed a weld on the study day and were defined as current welders. There was no significant difference in ethnicity, smoking habits, and years of work experience of the current welders compared with the 35 ex-welders and 40 non-welders.

The current welders were younger (mean (SD) age 36.9 (11.1) years) than the exwelders (41.2 (13.7)) and non-welders (39.6 (13.7) and had significantly greater mean total

Table 4 Factors associated with having work related respiratory symptoms (odds ratios shown both unadjusted and adjusted)

\begin{tabular}{|c|c|c|c|c|}
\hline & $\begin{array}{l}\text { Work related } \\
\text { symptoms }(n=31)\end{array}$ & $\begin{array}{l}\text { No work related } \\
\text { symptoms }(n=106)\end{array}$ & $\begin{array}{l}\text { Odds ratio } \\
(95 \% \text { CI) }\end{array}$ & $\begin{array}{l}\text { Adjusted odds } \\
\text { ratio }(95 \% \text { CI })+\end{array}$ \\
\hline \multicolumn{5}{|l|}{ Smoking: } \\
\hline Never & 9 & 41 & $1.0^{\star}$ & $1.0^{\star}$ \\
\hline Ex-smoker & 7 & 22 & $1.5(0.5$ to 4.4$)$ & 1.6 (0.5to5.3) \\
\hline Current & 15 & 43 & $1.6(0.6$ to 4.0$)$ & $1.9(0.7$ to 5.0$)$ \\
\hline \multicolumn{5}{|l|}{ Ethnicity: } \\
\hline Other & 26 & 76 & $1.0^{\star}$ & $1.0^{\star}$ \\
\hline Polynesian & 5 & 30 & 0.5 (0.2to1.4) & $0.4(0.1$ to 1.2$)$ \\
\hline \multicolumn{5}{|l|}{ Age: } \\
\hline $17-24$ & 4 & 14 & $1.0^{\star}$ & $1.0^{\star}$ \\
\hline $25-40$ & 13 & 48 & $1.0(0.3$ to 3.4$)$ & 0.7 (0.2to 2.6$)$ \\
\hline$>40$ & 14 & 44 & 1.1 (0.3to3.9) & 0.6 (0.1 to 2.8$)$ \\
\hline \multicolumn{5}{|c|}{$\begin{array}{l}\text { Time spent currently welding in confined spaces } \\
(\%) \text { : }\end{array}$} \\
\hline $0-2$ & 16 & 79 & $1.0^{\star}$ & $1.0^{\star}$ \\
\hline $2-10$ & 4 & 12 & 1.7 (0.5to5.8) & $1.3(0.3$ to 5.0$)$ \\
\hline$>10$ & 11 & 15 & 3.6 (1.4to 9.3$)$ & 2.8 (1.0to8.3) \\
\hline \multicolumn{5}{|c|}{ Total exposure index $(y)$ : } \\
\hline $0-4$ & 15 & 70 & $1.0^{\star}$ & $1.0^{\star}$ \\
\hline $4-10$ & 7 & 21 & 1.6 (0.6to4.3) & 1.5 (0.5to 4.8$)$ \\
\hline$>10$ & 9 & 15 & 2.8 (1.0to7.6) & $3.0(0.9$ to 10.5$)$ \\
\hline
\end{tabular}

$\star$ Reference category.

† Adjusted for all other factors in table. 
exposure index $(7.7$ years $(6.7), \mathrm{p}=0.02)$ than ex-welders (4.7 (5.6)).

All three groups had worked for a similar duration of time in the manufacturing industry; current welders for a mean (SD) of 15.9 (10.4) years, ex-welders for a mean of 17.4 (12.7) years, and non-welders for 16.3 (15.2) years.

Thirteen workers $(9.5 \%)$ complained of symptoms of chronic bronchitis and 10 of these reported the duration of these to be at least two years. All subsequent analysis of chronic bronchitis refers to this group. Thirty one workers $(22.6 \%)$ complained of one or more work related respiratory symptom. Table 2 compares sex, ethnicity, smoking habits, and reporting of respiratory symptoms between the job categories of welders, ex-welders, and non-welder.

Chronic bronchitis was more prevalent in current welders who smoked $(13.8 \%)$ than in current welders who had never smoked (4.3\%). Likewise, chronic bronchitis was more prevalent in non-welders who currently smoked $(11.8 \%)$ than in non-welders who had never smoked $(0 \%)$.

The report of any work related respiratory symptom was less prevalent in current welders who smoked $(24.1 \%)$ than in current welders who never smoked $(39.1 \%)$ and more prevalent in non-welders who smoked $(23.5 \%)$ than in non-welders who never smoked $(0 \%)$.

The mean (SD) percentage predicted values of $\mathrm{FEV}_{1}$ and FVC did not differ significantly between those with and without chronic bronchitis; mean $\mathrm{FEV}_{1}$ for those workers with chronic bronchitis (94.0 (19.9)), no bronchitis (103.4 (14.8)), $\mathrm{p}=0.06$; mean FVC for those with chronic bronchitis (113.6 (15.0)), no bronchitis $(110.3$ (15.7)), $\mathrm{p}=0.52$.

However, the mean FEV\% was significantly lower in workers with chronic bronchitis (mean 0.68 (SD 0.13)) than in those without chronic bronchitis $(0.78(0.09))$, and when taken together with the reduction in mean percentage predicted PEF (74.9 (18.5)) compared with people without bronchitis (93.5 (21.3)), this suggests a degree of airways obstruction in this group.

Furthermore, when a cut off of an FEV\% of $<0.70$ was used, five workers with chronic bronchitis had this degree of obstruction compared with 18 workers without chronic bronchitis (OR 5.83, 95\% CI 1.7 to 19.6). Within the group reporting chronic bronchitis, those workers with airways obstruction complained of regular cough and phlegm for a mean of 11.6 (7.9) years compared with 4.4 (3.4) years for those without airways obstruction.

The mean $\mathrm{FEV}_{1}$ in those with at least one work related symptoms was significantly lower (95.7 (14.1)) than in those without these symptoms $(104.8(15.1)), \mathrm{p}=0.004$. Again, the prevalence of a lowered FEV\% $(<0.70)$ was higher in those with these symptoms (30\%) than in those without these symptoms (13.6\%), OR $2.72,95 \%$ CI 1.06 to 6.99 .

Table 3 shows the unadjusted and adjusted ORs (and 95\% CIs) for risk factors associated with chronic bronchitis, and table 4 shows the results of the analysis used to identify the risk factors associated with the presence of at least one work related respiratory symptom.

\section{Discussion}

The association between exposures encountered as a welder and the development of chronic bronchitis and other respiratory symptoms has been investigated previously in many studies, ${ }^{5-7} 9$ 16-19 although not all studies have found a higher prevalence of chronic bronchitis in current welders ${ }^{70}$ than in non-welding controls.

What often complicates the interpretation of, and comparison between, such studies is, firstly, the role of cigarette smoking in the aetiology of the symptoms, and, secondly, accurately measuring lifetime exposures to welding fume. For example, although many studies agree that chronic bronchitis is more common in welders, some only note this in non-smoking welders, ${ }^{19}$ smoking welders, ${ }^{67}$ or in both current smokers and non-smokers. ${ }^{5} 17$

It is likely that the development of chronic bronchitis and other work related respiratory symptoms in welders relate to exposure to a combination of dusts (which may act as irritants in their own right) and irritant gases in the workplace as well as the effects of smoking. Quite how these two aetiological factors interact is not known, although it is possible that smoking may alter the handling of agents encountered in the workplace, by interfering with the normal mucocilliary clearance or by more complex mechanisms. ${ }^{21}$ Furthermore, recent work in asthmatic people suggests that inhaled irritants may alter the handling of inhaled allergens, ${ }^{22}$ although how this relates to potential allergens in the workplace is not known.

Individual susceptibility to the effects of these irritants - such as the presence of preexisting bronchial hyperresponsiveness or atopy - is likely to influence the response of each individual worker.

Only heavily exposed people seemed to be at excess risk of developing chronic bronchitis and work related respiratory symptoms in this study after taking into account current smoking habit. In fact, the equivalent work practice associated with being included in the highest total exposure index category ( $\geqslant 10$ years) is welding for $25 \%$ of the working day for 40 years or for $50 \%$ of the working day for 20 years.

The presence of chronic bronchitis in this study was overwhelmingly associated with a measure of cigarette smoking as well as a cumulative measure of lifetime exposure to welding fume. Furthermore, within these workers with chronic bronchitis, there did seem to be two discrete populations of workers; those with symptoms of chronic bronchitis of generally short duration, and those with longer term symptoms and associated airways obstruction. It is plausible that different sized particles within the welding fume are able to act independently on different sized airways within the lung, to produce a combination of both chronic bronchitis and airways disease in 
a similar manner to that suggested for coal workers. $^{23}$

The specific agents causing these findings are not known, although exposure to $\mathrm{NO}_{2}$ alone has been linked to respiratory symptoms in metal cutting, ${ }^{24}$ exaggerated levels of bronchial responsiveness, ${ }^{25}$ and morphological changes $^{26}$ in the human airway after exposure. Also, as $\mathrm{NO}_{2}$ is relatively insoluble in the human airway, considerable amounts may be inhaled before any irritant effect is noted by the workers. ${ }^{27}$ It seems intuitively possible that exposure to $\mathrm{NO}_{2}$ is an important contributor to the development of chronic bronchitis. Similarly, ozone exposure has been implicated ${ }^{18} 28$ in the aetiology of respiratory disease and chromium exposure may be an important determinant of disease in stainless steel welders. ${ }^{1}$

As this was a cross sectional study, it is likely that we have underestimated the association of welding with chronic bronchitis, as workers with intolerable symptoms with or without disability related to airways obstruction may leave the industry. ${ }^{29}$ The natural history (both at incidence and after exposure ends) of these symptoms is important to understand, however, and is largely uninvestigated. One comprehensive study of British welders in shipyards ${ }^{6}$ identified smoking (when first seen in the study) as the most important determinant of subsequently developing chronic bronchitis over an average follow up period of seven years. Conversely, recovery from chronic bronchitis was related to stopping smoking in younger workers with better that average lung function. It could be postulated, perhaps, that the workers in our study with symptoms of chronic bronchitis and no evidence of airways obstruction are more likely to complain of transient or intermittent symptoms that may regress if smoking is discontinued, whereas those with airways obstruction are likely to be continually symptomatic. A subsequent publication from the same study ${ }^{30}$ suggested that people not currently working at the time of follow up had originally complained of more respiratory symptoms.

The presence of work related respiratory symptoms in this study was significantly related to a marker of heavy exposure to welding fume (confined space welding) and was associated with increasing cumulative exposure to welding as judged by the exposure index. This group of workers reported symptoms to be worse at work or improving on rest days, and are classically thought to represent workers with occupational asthma as well as some workers with exercise related symptoms. As this study did not investigate this group further, we cannot comment on the underlying conditions related to the reporting of these symptoms. It is a fair assumption that at least a proportion will have asthma related to workplace exposure.

In summary, this study has documented chronic bronchitis and work related respiratory symptoms in welders performing predominantly gas metal arc welding (particularly MIG) and TIG welding. Chronic bronchitis related independently to smoking habits, exposure to welding fumes, and the presence of work related respiratory symptoms were associated with a measure of heavy exposure to welding fume.

Although the main causative agent is not known, there would clearly be benefits both from eliminating cigarette smoking and reducing exposure to welding fume through the proper use of protective equipment.

The Wellington Asthma Research Group is funded by a type 1 programme grant and this project was funded by a limited budget grant from the Health Research Council of New Zealand. We thank Hazel Armstrong of the New Zealand Engineers Union and the Union delegates, management, and workers who participated in, or assisted with, the study. DF was funded in part by the Northern Regional Health Authority of the United Kingdom.

1 Sferlazza S, Beckett W. The respiratory health of welders. Am Rev Respir Dis 1991;143:1134-48.

2 Stern R, Berlin A, Fletcher A, et al. International conference on health hazards and biological effects of welding fumes and gases. Occup Environ Health 1986;57:237-46.

3 Ross D. Welders metal fume fever. F Soc Occup Med 1974;24:125-9.

4 Attfield M, 3 D. Radiological abnormalities in electric arc welders. Br F Ind Med 1978;35:117-22.

5 Ozdemir O, Numanoglu N, Gonullu U, et al. Chronic effects of welding exposure on pulmonary function tests and respiratory symptoms. Occup Environ Med 1995;52:800-3. Chin D, Stevenson I, Cotes J. Longitudinal respiratory survey of shipyard workers: effects of trade and atopic status. Br F Ind Med 1990;47:83-90.

7 Hayden S, Pincock A, Hayden J, et al. Respiratory symptoms and pulmonary function of welders in the engineering industry. Thorax 1984;39:442-7.

8 Fogh A, Frost J, Georg J. Respiratory symptoms and pulmonary function in welders. Ann Occup Hyg 1969;12:213-8.

9 Dryson E, Rogers D. Exposure to fumes in typical New Zealand welding operations. New Zealand Medical fournal 1991;104:365-7.

10 Fishwick D, Bradshaw LM, Slater T, et al. Respiratory symptoms, across shift lung function changes and lifetime exposures in New Zealand welders. Scand $\mathcal{f}$ Work Environ Health 1997;23:351-8.

11 Burney P, Luczynska C, Chinn S, et al. The European Community Respiratory Health Survey. Eur Respir $\mathcal{F} 1994$; 7:954-60.

12 Quanjier $\mathrm{PhH}$, ed. Standardisation of lung function tests1993 update. Report of working party for the European Community for steel and coal. Eur Respir F 1993;6(suppl 16).

13 SAS language guide for personal computers. Carey, NC: SAS Institute, 1988.

14 Mantel N, Haenszel WH. Statistical aspects of the analysis of data from retrospective studies of disease. $\mathcal{F}$ Natl Cancer Inst 1959;22:719-48.

15 Harrell F. The LOGIST procedure. In: SAS supplemental library users guide. Cary, NC: SAS Institute, 1983.

16 Cotes J, Feinmann E, Male V, et al. Respiratory symptoms and impairment in shipyard welders and caulker/burners. Br f Ind Med 1989;46:292-301.

17 Wang Z, Larsson K, Malmberg P, et al. Asthma, lung function and bronchial responsiveness in welders. Am $\mathcal{F}$ Ind Med 1994;26:741-54.

18 Sjogren B, Ulfvarson U. Respiratory symptoms and pulmonary function among welders working with aluminium, stainless steel, and railroad tracks. Scand $\mathcal{F}$ Work Environ Health 1985;11:27-32.

19 Keimig D, Pomrehn P, Burmeister L. Respiratory symptoms and pulmonary function in welders of mild steel: a cross-sectional study. Am f Ind Med 1983;4:489-99.

20 McMillan G. Studies of the health of welders in naval dockyards. Ann Occup Hyg 1978;21:377-92.

21 Becklake M. Chronic airflow limitation: its relationship to work in dusty occupations. Chest 1988;4:608-17.

22 Tunnicliffe W, Burge P, Ayres J. Effect of domestic concentrations of nitrogen dioxide on airway responses to inhaled allergen in asthmatic patients. Lancet 1994;344:1733-66.

23 Seaton A. Coal and the lung. Thorax 1983;38:241-43.

24 Norwood W, Wisehart D, Earl C. Nitrogen dioxide poisoning due to metal cutting with an oxyacetylene torch. $\mathcal{f}$ Occup Med 1966;8:301-6.

25 Folinsbee L. Does nitrogen dioxide exposure increase airways responsiveness? Toxicol Ind Health 1992;8:273-83.

26 Devalia J, Sapsford R, Cundell D, et al. Human bronchial epithelial cell dysfunction following in vitro exposure to nitrogen dioxide. Eur Respir F 1993;6:1308-16.

27 Newman-Taylor A. Respiratory irritants encountered at work. Thorax 1996;51:541-5.

28 Aris R, Christian D, Hearne P, et al. Ozone induced airway inflammation in human subjects as determined by airway lavage and biopsy. Am Rev Respir Dis 1993;148:1363-72.

29 Checkoway H, Pearce N, Crawford-Brown D. Research methods in occupational epidemiology. New York: Oxford University Press, 1989.

30 Chinn D, Cotes J, Gamal FE, et al. Respiratory health of young shipyard welders and other tradesmen studied cross sectionally and longitudinally. Occup Environ Med 1995;55: $33-42$. 